\title{
Corymbiform syphilis associated with three other sexually transmitted infections*
}

\author{
John Verrinder Veasey ${ }^{1}$ \\ Felipe Henrique Yazawa Santos ${ }^{2}$
}

Lyvia Almeida Nascimento Salem ${ }^{2}$

DOI: http:/ / dx.doi.org/10.1590/abd1806-4841.20186850

\begin{abstract}
Secondary syphilis can have different clinical presentations, with corymbiform rash as its rarest manifestation. The disease is characterized by a central papule surrounded by smaller ones. We report the case of a man who has sex with man with corymbiform syphilis. The patient was subsequently diagnosed with HIV infection, hepatitis B, non-gonococcal urethritis, as well as infection of the central nervous system by treponema. This case not only illustrates a rare presentation of secondary syphilis, but also demonstrates the importance of further investigation of sexually transmitted infections, particularly among at-risk patients.
\end{abstract}

Keywords: Hepatitis B; HIV; Homosexuality, male; Neurosyphilis; Risk groups; Sexually Transmitted Diseases; Skin; Syphilis; Syphilis, cutaneous

\section{INTRODUCTION}

Syphilis is a sexually transmitted infection (STI) caused by the bacterium Treponema pallidum. The disease is divided into stages according to its duration: primary, secondary, latent, and tertiary syphilis. ${ }^{1}$ The dermatological manifestations of the secondary stage are diverse, with reports of macular, papular, nodular, and lichenoid lesions, among others. The presentation of secondary syphilis with corymbiform lesions is extremely rare. It is characterized by larger papules surrounded by smaller satellite lesions, making differential diagnosis with sarcoidosis, amyloidosis, and Sweet's syndrome..$^{2-4}$

Patients diagnosed with syphilis should be investigated for other STIs, such as HIV infection and hepatitis B and C. Studies have shown that HIV infection may be present in more than a quarter of those diagnosed with syphilis. In some regions of the United States, this figure may reach as high as $70 \% .{ }^{5}$ Patients coinfected with HIV and Treponema pallidum may present with rare clinical manifestations, as well as atypical evolutions of the natural history of syphilis, such as concomitance of stages. ${ }^{1,6}$

Sexual risk behaviors and poor adherence to preventive methods make men who have sex with men (MSM) a population that is especially vulnerable to STIs. ${ }^{5,7}$ Despite global efforts over the years to contain syphilis and HIV - especially among those with risk behavior -, the occurrence of new infections among MSM continues to grow. ${ }^{7}$

We report the case of a patient with corymbiform syphilis who was also diagnosed with three other STIs during follow-up: hepatitis B, HIV infection, and non-gonococcal urethritis, as well as neurosyphilis.

\section{CASE REPORT}

We report a 29-year-old MSM patient with no pathological history. He reported sudden onset of asymptomatic disseminated dermatosis characterized by erythematous papules clustered in a flowerlike arrangement (corymbiform arrangement) associated with erythematous macules, some with a squamous ring (Biett's collarette), and annular plaques on the back of the hands. The patient reported that the lesions started on the upper limbs with posterior dissemination to the genitalia, palms, and soles after one month of evolution (Figures 1 and 2). We observed an asymptomatic ulcer with slightly raised borders and a clean base in the perianal region (Figure 3).

Received on 22.12.2016.

Approved by the Advisory Board and accepted for publication on 11.03.2017.

* Work performed at the Dermatology Clinic at Santa Casa de São Paulo - São Paulo (SP), Brazil.

Financial support: None.

Conflict of interest: None.

1 Infeccious Disease Division of the Dermatology Clinic at Santa Casa de São Paulo - São Paulo (SP), Brazil.

2 Dermatology Clinic at Santa Casa de São Paulo - São Paulo (SP), Brazil.

MAILING ADDRESS:

John Verrinder Veasey

E-mail: johnveasey@uol.com.br 

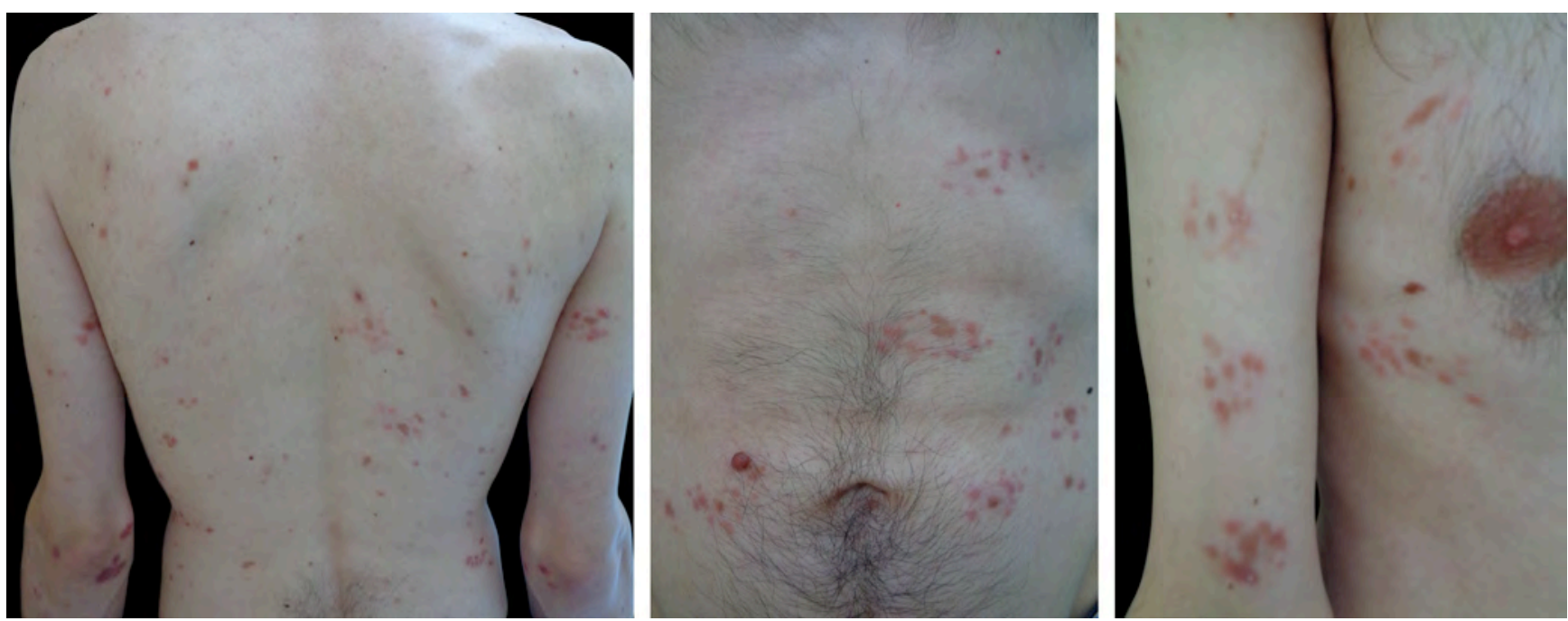

FIGURE 1: Corymbiform secondary syphilis with lesions disseminated throughout the body formed by a central papule surrounded by smaller ones
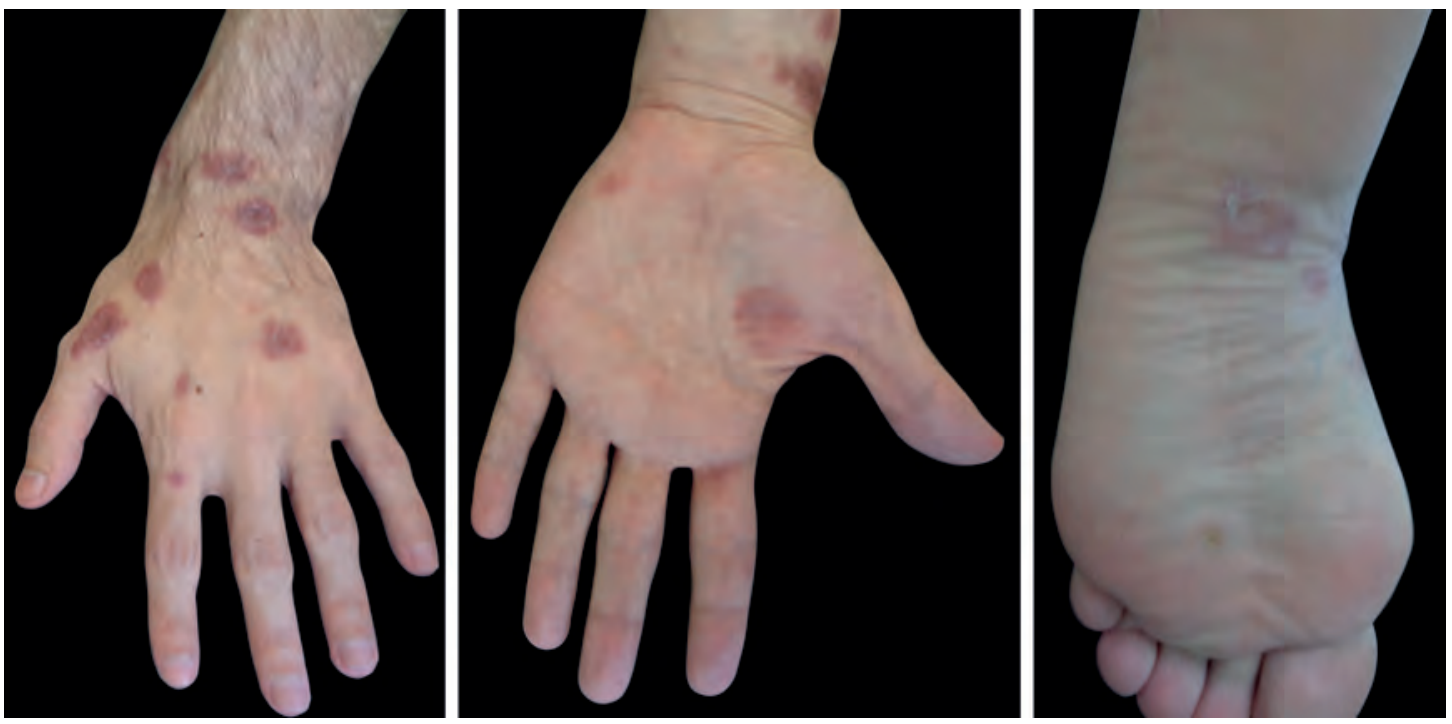

FIGURE 2:

Palmoplantar involvement with

annular plaques, some with peripheral desquamation

We considered the diagnostic hypothesis of corymbiform secondary syphilis concomitant with rectal chancre. After a biopsy of the lesion on the back of the hands, we requested serologies for HIV, hepatitis $B$, hepatitis $C$, and syphilis. The results showed VDRL positive with a titer of 1:1024, positive treponemal screening test (CMIA), positive HIV serologic test, positive Anti-HBs and Anti-HBc, and non-reactive HBsAg. Histopathological examination of the hand lesion was compatible with the clinical hypothesis of syphilis.

After prescribing a treatment with benzathine penicillin, we referred the patient to an HIV reference center due to his positive HIV and hepatitis B test results. We also requested a cerebrospinal fluid (CSF) analysis to assess syphilitic involvement of the central nervous system.

In the return visit, skin lesions evolved with progressive regression, and the anal ulcer lesion was fully healed. The patient complained of urethral discharge, dysuria, and increased testicular volume four days before the consultation. On examination, in addition to the clear egg-white color urethral discharge, we observed scrotal swelling and pain on palpation of the right testicle and epididymis (Figure 4). Bacterioscopic analysis of the urethral secretion smear showed inflammatory cells lacking gram-negative diplococci. CSF analysis showed a clear and colorless sample with 16 cells/ $\mathrm{mm}^{3}$ (84\% lymphocytes, $1 \%$ eosinophils, $6 \%$ monocytes, $1 \%$ neutrophils, $8 \%$ plasma cells), protein level of $63 \mathrm{mg} / \mathrm{dl}$, glucose $53 \mathrm{mg} / \mathrm{dl}$, positive Pandy's test, and VDRL positive with a titer of $1 / 2$. These findings allowed the confirmation of infection of the central nervous system by treponema.

We introduced treatment of urethral discharge and epididymitis with ciprofloxacin 500mg every 12 hours for 14 days associated with azithromycin $1 \mathrm{~g}$ in a single dose. We explained the di- 


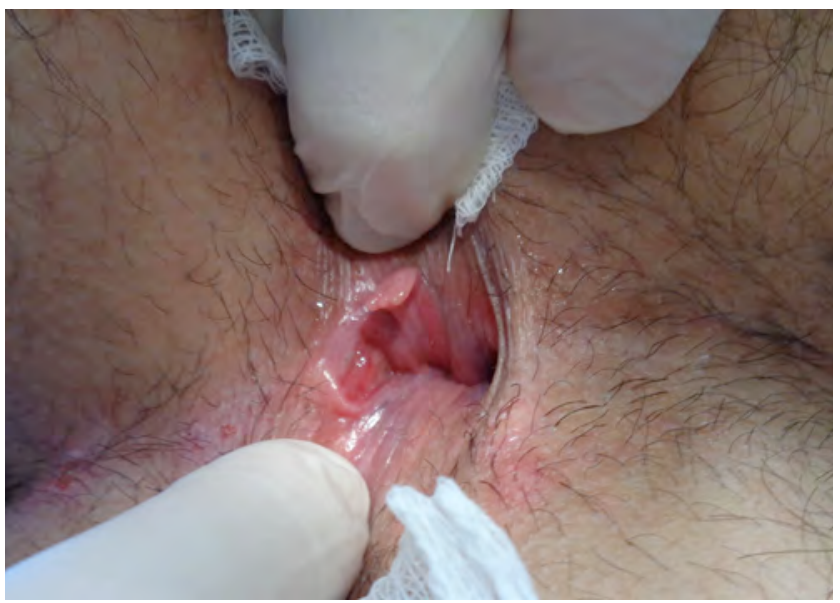

FigURE 3: Anal chancre: an asymptomatic ulcer located at the posterior anal margin with precise limits and clean base
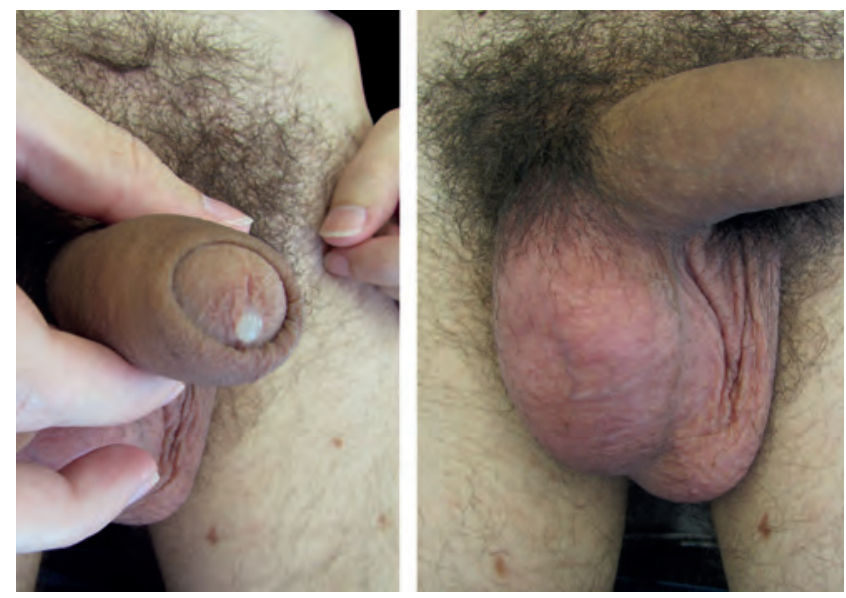

FIGURE 4: Non-gonococcal urethritis: non-purulent urethral discharge associated with scrotal edema, painful on palpation

ing to the MS, there has been a trend towards an increase in the proportion of MSM cases in the last ten years, from 35.3\% in 2006 to $45.4 \%$ in $2015 .{ }^{9}$

HIV-infected patients who contract syphilis may present with atypical clinical manifestations. Over $70 \%$ of patients have more than one hard chancre in the primary stage of syphilis, and $25 \%$ have concomitant hard chancre with secondary lesions, as in the present case. ${ }^{6}$

Approximately one third of patients with early syphilis have Treponema pallidum invasion into CSF regardless of their HIV serology. However, most new cases of neurosyphilis in HIV-infected individuals are identified in the early stages of syphilis, as in our patient. In addition, a recent correlation has been reported between abnormal CSF findings suggestive of neurosyphilis and advanced HIV disease. ${ }^{6}$

In Brazil, STI clinical management is based mainly on the syndromic approach, since the molecular diagnosis of STI is not routinely available in the Brazilian public health system..$^{3,10}$ The genital discharge presented by our patient was clinically characterized as non-gonococcal, which was confirmed by the absence of gram-negative diplococci in the bacterioscopic examination. In this case, the therapeutic approach indicated is treatment for chlamydia - responsible for $50 \%$ of these cases - with return scheduling for improvement evaluation. ${ }^{3}$

The present case is notable not only for the rarity of this secondary syphilis presentation, but also for demonstrating the importance of the investigation of other STIs, especially among at-risk patients. We must be prepared to investigate, diagnose, and treat complex cases such as the one described here. $\square$ indicate that while $0.39 \%$ of the general population is living with HIV in Brazil, the prevalence among MSM grows to $10.5 \% .{ }^{8}$ Accord- 


\section{REFERENCES}

1. Veasey JV, Lellis RF, Boin MF, Porto PL, Chen JC. Papulo-nodular secondary syphilis: a rare clinic presentation confirmed by serologic and histologic exams. An Bras Dermatol. 2016;91:205-7.

2. Baughn RE, Musher DM. Secondary Syphilitic Lesions. Clin Microbiol Rev. 2005:18:205-16.

3. Alessi E, Innocenti M, Ragusa G. Secondary syphilis. Clinical morphology and histopathology. Am J Dermatopathol. 1983;5:11-7.

4. Gonçalves SV, Valente NY, Passaro EM, Paiva DL, Dantas FL, Kakizaki P. Corymbiform nodular amyloidosis.. An Bras Dermatol. 2012;87:757-60.

5. DeSilva M, Hedberg K, Robinson B, Toevs K, Neblett-Fanfair R, Petrosky E. A casecontrol study evaluating the role of internet meet-up sites and mobile telephone applications in influencing a syphilis outbreak: Multnomah County, Oregon, USA 2014. Sex Transm Infect. 2016;92:353-8
6. Zetola NM, Klausner JD. Syphilis and HIV Infection: An Update. Clin Infect Dis. 2007;44:1222-8

7. Brosh-Nissimov T, Mor Z, Avramovich E, Katchman E, Avidor B, Mor O, et al. Syphilis Outbreak among Men who Have Sex with Men, Tel Aviv, Israel, 2008-2009. Isr Med Assoc J. 2012;14:152-6.

8. Unaids.org.br [Internet]. Estatísticas. Fonte: Relatórios mais recentes do UNAIDS. Resumo global da epidemia de AIDS [acesso 19 dez 2016]. Disponivel em: http:// unaids.org.br/estatisticas/.

9. Brasil. Ministério da Saúde. Secretaria de Vigilância em Saúde. Boletim Epidemiológico. Aids e DST. Brasilia: Ministério da Saúde; 2016.

10. Cunha CB, Friedman RK, de Boni RB, Gaydos C, Guimarães MR, Siqueira BH, et al. Chlamydia trachomatis, Neisseria gonorrhoeae and syphilis among men who have sex with men in Brazil. BMC Public Health. 2015;15:686.

How to cite this article: Veasey JV, Salem LAN, Santos FHY. Corymbiform syphilis associated with three other sexually transmitted infections. An Bras Dermatol. 2018;93(1):129-32. 